\title{
Percutaneous Coronary Intervention in Chronic Total Occlusion of Anomalous Right Coronary Artery
}

\author{
Sanjay C. Porwal'1, H. Vishwanath¹, Rajesh Tasgaonkar'1, Tulsee Sitapara², Ashok Thakkar² \\ ${ }^{1}$ KLES Dr. Prabhakar Kore Hospital \& Medical Research Centre, Belgaum, India \\ ${ }^{2}$ Department of Clinical Trials, Sahajanand Medical Technologies Pvt. Ltd., Surat, India \\ Email: drsanjayporwal@gmail.com
}

Received 24 March 2014; revised 22 April 2014; accepted 10 May 2014

Copyright (C) 2014 by authors and Scientific Research Publishing Inc.

This work is licensed under the Creative Commons Attribution International License (CC BY). http://creativecommons.org/licenses/by/4.0/

(c) (i) Open Access

\begin{abstract}
Chronic total occlusion of an anomalous right coronary artery arising from left coronary sinus is uncommon. We are describing a case of a 71 years old patient presented with severe chest pain along with exertional dyspnea with an inferior wall myocardial infarction. Coronary angiography showed anomalous right coronary artery originating from left coronary sinus having chronic total occlusion in proximal portion and normal left anterior descending artery and left circumflex artery. We were successful in implanting the two stents at an occlusive region with good angiographic results.
\end{abstract}

Keywords

Anomalous Right Coronary Artery, Percutaneous Coronary Intervention, Coronary Angiography

\section{Introduction}

Coronary arteries of anomalous origin are rare. The clinical importance of coronary artery anomaly may vary between asymptomatic harmless conditions and hazardous lesions, which may even lead to sudden cardiac death (SCD). Coronary anomalies may be classified into 2 groups according to their anatomical characteristics: anomalies of origin and distribution and anomalies of termination. Coronary artery originating from contralateral sinus of Valsalva carries the highest risk [1]. Anomalous origin of the right coronary artery (RCA) from the left sinus of Valsalva (LSOV) has been found in $6 \%-27 \%$ of the patients with coronary anomalies [2] and in $0.02 \%$ $-0.17 \%$ of coronary angiogram. The treatment schedule of anomalous origin RCA complicated with coronary artery diseases (CAD) included drug conservative therapy, PCI and surgical correction or/and coronary artery 
bypass graft. However, past studies have indicated the subjects of RCA anomalous origin lived to adulthood but developed CAD and did not show superfluous advantages from surgical correction [3] [4]. It is noteworthy that anomalies cause technical problems during coronary angiography as well as during percutaneous transluminal coronary angioplasty (PTCA). We are presenting a case of an old patient who experienced myocardial infarction as a result of chronic total occlusion in RCA which had anomalous origin of left coronary cusp.

\section{Case Report}

A 71 years old female patient, hypertensive and nondiabetic, admitted to our hospital for the severe chest pain along with exertional dyspnea. She has been diagnosed with inferior wall myocardial infarction (IWMI) six months back.

Electrocardiogram was suggestive of old IWMI. Echocardiography evaluation revealed concentric left ventricular (LV) hypertrophy, normal resting LV systolic function (ejection fraction $=60 \%$ ), no regional wall motion abnormality, mitral annular calcification, normal pulmonary arterial pressure and type I diastolic dysfunction. Coronary angiography showed dominant RCA (type-III vessel) with anomalous origin from left coronary sinus having chronic total occlusion in proximal portion (Figure 1) and normal left anterior descending artery and left circumflex artery (Figure 1). We planned to perform PTCA for RCA in view of chronic total occlusion.

Anomalous right coronary ostium was selectively engaged by using 3.5 6F IKARI catheter launcher guiding catheter (Terumo, Heartrail II) using right trans-femoral approach. Chronic total occlusion of proximal-RCA was crossed with $0.014 " \times 180 \mathrm{~cm}$ Fielder XT guidewire (Asahi Intecc Co., Ltd., Japan) with the support of microcatheter (Figure 2). A contralateral injection was given through collaterals to fill distal RCA.

Fielder XT wire guide wire was then exchanged with 0.014" $\times 190 \mathrm{~cm}$ BMW guide wire (Abbott Vascular, USA). Pre-dilatation of the lesion was carried out by $2.5 \times 15 \mathrm{~mm}$ Maverick-II balloon (Monorail) at $6-8 \mathrm{~atm}$ pressure for $30 \mathrm{sec}$. However, post balloon check angiogram showed 30\%-40\% residual lesion. A $3.5 \times 32 \mathrm{~mm}$ drug eluting stent, Supralimus core ${ }^{\mathrm{TM}}$ (Sahajanand Medical Technologies Pvt Ltd., India), was deployed in mid RCA at $9-14$ atm pressure for $30 \mathrm{sec}$. Another Supralimus core ${ }^{\mathrm{TM}}$ stent (Figure 3) was deployed in proximal RCA overlapping the previous stent. In stent dilatation was done using $3.5 \times 15 \mathrm{~mm}$ Quantum Maverick II balloon (Monorail) at $12-26 \mathrm{~atm}$ pressure for $30 \mathrm{sec}$.
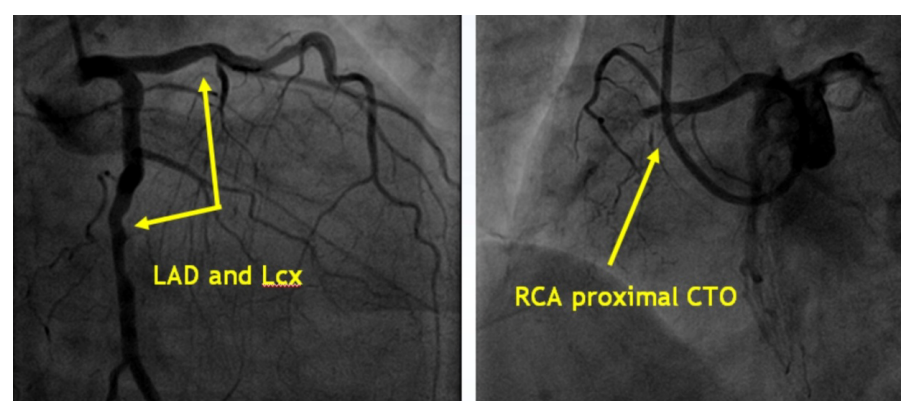

Figure 1. Normal left anterior descending artery and left circumflex artery and chronic total occlusion in proximal right coronary artery.

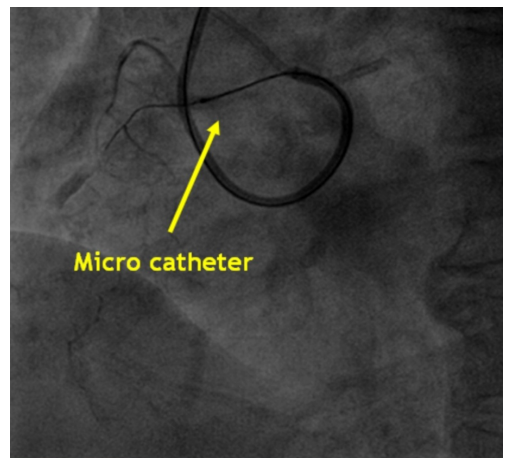

Figure 2. Use of Microcatheter. 

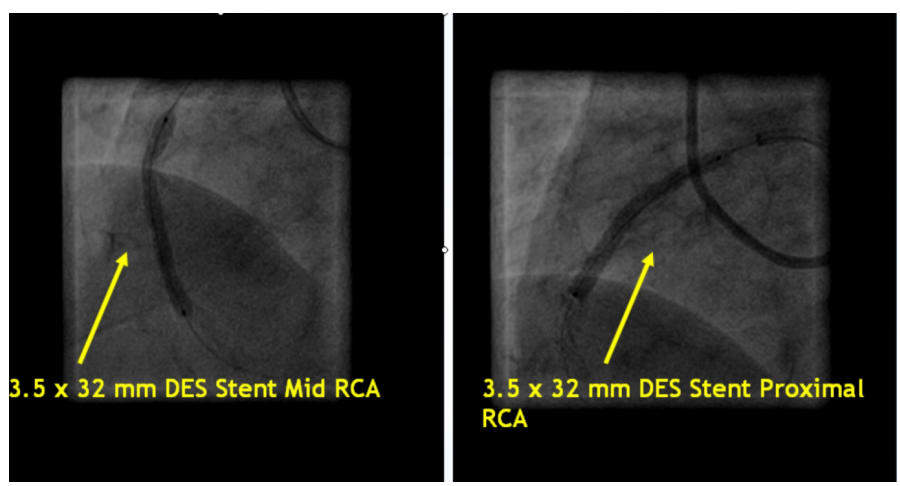

Figure 3. Stenting of each mid and proximal right coronary artery with $3.5 \times 32 \mathrm{~mm}$ Supralimus core ${ }^{\mathrm{TM}}$ stent.

Check angiogram showed well placed stent with TIMI III flow (Figure 4) and non residual stenosis or dissection or thrombus. The stay of patient in the was uneventful and he was discharged from the hospital along with clopidogrel and aspirin (Clopivas-AP, $150 \mathrm{mg}$ ) for 1 year as well as metoprolol (Metpure-XL, $50 \mathrm{mg}$ ) and ramipril (Cardace, $2.5 \mathrm{mg}$ ).

\section{Discussion}

The incidence of coronary artery anomalies varies from $0.3 \%$ to $1.3 \%$ [5]-[7]. However, with the development of cardiac imaging techniques the coronary anomalies have been increasingly reported nowadays. Topaz et al., reported the incidence of coronary anomalies $0.61 \%$ and also concluded anomalous origin of RCA as the most common anomaly in 13,010 patients with the incidence of $0.38 \%$ [6].

So far a variety of anomalous origins of RCA have been reported in the literature. According to previous studies, the most common anatomic site of anomalous RCA originated mainly at four locations: LCS, antetheca of the aortic wall, supracristal plane above the right coronary sinus (RCS) and left coronary system [8]-[11]. Praharaj, T., et al., reported anomalous origin of RCA from left sinus of the valsalva [12]. Elbasan, Z., et al., reported a case of anomaly of RCA with LAD [13].

Coronary intervention of RCA is technically challenging in patients with an anomalous artery. It demands a high degree of awareness and complete evaluation of the coronary artery anatomy and distribution in order to avoid complications.

A study by S. Turkmen et al., reported that branching of RCA from LSV was $0.10 \%$ comprising $8 \%$ of the total anomalies present [1]. Most of the anomalies are considered benign. Similar case was observed in our patients. A patient was observed with chronic total occlusion in anomalous RCA with Type I diastolic dysfunction. We performed PCI with excellent angiographic results.

It is very important, how we evaluate the anatomic site of anomaly of RCA. Selection of cannulation is based on various factors such as the angiographic results of LCA and occurrence frequency of anomalous RCA ostium. Any blinding operations may increase the dosage of the contrast agent, operation time, and additional radioactive damage and even increase the possibility of coronary artery dissection or aortic dissection and other serious complications [14]. Patients of anomalous RCA underwent selective PCI should go through a test of contrast enhanced CT angiography (CTA) to affirm originated sites, anatomic route and whether they are complicated with other congenital malformations. CTA is also advantageous in selecting the therapy and auxiliary PCI procedures [15]-[18].

Proper selection and skillful manipulation of guide catheter are the key factors for successful PCI of anomalous RCA [19]. Guide catheter selection should be done on the basis of origin site, anatomic ostium, and characteristics of lesion, vascular conditions, travel route, supporting requirement and other comprehensive considerations [20].

Manipulating skills must be needed during the PCI. Due to the anomalous anatomic origin of RCA, guide catheters are inevitably more difficult to be sound coaxialilty. Under such situation, using wisely a method of guiding the PCI wire "gone with the flow" and stepping it to the distal-RCA are more beneficial and even smoothens our work. Multi-wire anchoring technology can be used to lead the guide catheter to the appropriate place 


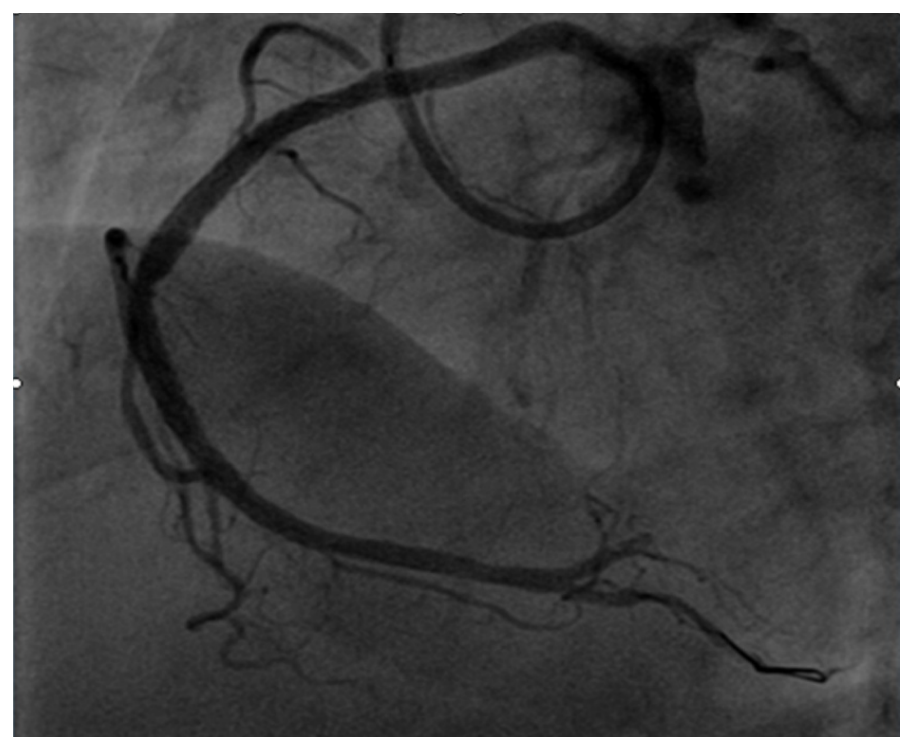

Figure 4. Post angiographic result with good TIMI III flow.

and complete the process of stent installment.

In summary, a case of chronic total occlusion of anomalous right coronary artery originating from left coronary sinus successfully underwent PCI.

\section{References}

[1] Turkmen, S., Cagliyan, C.E., Poyraz, F., Sercelik, A., Boduroglu, Y., Akilli, R.E., Balli, M. and Tekin, K. (2013) Coronary Arterial Anomalies in a Large Group of Patients Undergoing Coronary Angiography in Southeast Turkey. Folia Morphologica, 72, 123-127. http://dx.doi.org/10.5603/FM.2013.0020

[2] Taylor, A.J., Rogan, K.M. and Virmani, R. (1992) Sudden Cardiac Death Associated with Isolated Congenital Coronary Artery Anomalies. Journal of the American College of Cardiology, 20, 640-647. http://dx.doi.org/10.1016/0735-1097(92)90019-J

[3] Krasuski, R.A., Magyar, D., Hart, S., Kalahasti, V., Lorber, R., Hobbs, R., Pettersson, G. and Blackstone, E. (2011) Long-Term Outcome and Impact of Surgery on Adults with Coronary Arteries Originating from the Opposite Coronary Cusp. Circulation, 123, 154-162. http://dx.doi.org/10.1161/CIRCULATIONAHA.109.921106

[4] Kron, I.L. (2012) The Best Approach to Repair Anomalous Origin of the Right Coronary Artery. European Journal of Cardio-Thoracic Surgery: Official Journal of the European Association for Cardio-Thoracic Surgery, 41, 290. http://dx.doi.org/10.1093/ejcts/ezr022

[5] Yamanaka, O. and Hobbs, R.E. (1990) Coronary Artery Anomalies in 126,595 Patients Undergoing Coronary Arteriography. Catheterization and Cardiovascular Diagnosis, 21, 28-40. http://dx.doi.org/10.1002/ccd.1810210110

[6] Topaz, O., DiSciascio, G., Goudreau, E., Cowley, M.J., Nath, A., Kohli, R.S. and Vetrovec, G.W. (1990) Coronary Angioplasty of Anomalous Coronary Arteries: Notes on Technical Aspects. Catheterization and Cardiovascular Diagnosis, 21, 106-111. http://dx.doi.org/10.1002/ccd.1810210213

[7] Click, R.L., Holmes, D.R., Vlietstra, R.E., Kosinski, A.S. and Kronmal, R.A. (1989) Anomalous Coronary Arteries: Location, Degree of Atherosclerosis and Effect on Survival-A Report from the Coronary Artery Surgery Study. Journal of the American College of Cardiology, 13, 531-537. http://dx.doi.org/10.1016/0735-1097(89)90588-3

[8] Yurtdas, M. and Gulen, O. (2012) Anomalous Origin of the Right Coronary Artery from the Left Anterior Descending Artery: Review of the Literature. Cardiology Journal, 19, 122-129. http://dx.doi.org/10.5603/CJ.2012.0023

[9] Rao, U., Agrawal, B. and Dwivedi, S. (2013) Anomalous Origin of Right Coronary Artery from Left Coronary Sinus. European Heart Journal Cardiovascular Imaging, 14, 23. http://dx.doi.org/10.1093/ehjci/jes147

[10] Halim, S.A., Wang, A. and Harrison, J.K. (2011) Anomalous Right Coronary Artery Origin from the Pulmonary Artery (Arcapa) Coexisting with Obstructive Atherosclerotic Disease of the Left Coronary Artery. The Journal of Invasive Cardiology, 23, E260-E261.

[11] Lee, H.J., Hong, Y.J., Kim, H.Y., Lee, J., Hur, J., Choi, B.W., Chang, H.J., Nam, J.E., Choe, K.O. and Kim, Y.J. (2012) Anomalous Origin of the Right Coronary Artery from the Left Coronary Sinus with an Interarterial Course: Subtypes 
and Clinical Importance. Radiology, 262, 101-108. http://dx.doi.org/10.1148/radiol.11110823

[12] Praharaj, T.K. and Ray, G. (2001) Percutaneous Transluminal Coronary Angioplasty with Stenting of Anomalous Right Coronary Artery Originating from Left Sinus of Valsalva Using the Voda Guiding Catheter: A Report of Two Cases. Indian Heart Journal, 53, 79-82.

[13] Elbasan, Z., Şahin, D.Y., Gür, M. and Çayli, M. (2013) A Patient with Anomalous Right Coronary Artery Originating from the Left Anterior Descending Artery Who Underwent Complex Percutaneous Coronary Intervention: A Case Report. Journal of Cardiology Cases, 8, e46-e48. http://dx.doi.org/10.1016/j.jccase.2013.03.012

[14] Saito, T., Noguchi, K. and Oikawa, T. (2011) Iatrogenic Dissection of the Anomalous-Origin Right Coronary Artery and Left Sinus of Valsalva. The Journal of Invasive Cardiology, 23, E51-E53.

[15] Wilentz, J.R. and Hecht, H.S. (2009) Utility of Coronary Computed Tomography Guidance for Intervention of an Anomalous Right Coronary Artery. The Journal of Invasive Cardiology, 21, 374-376.

[16] Andreou, A.Y., Petrou, P.M., Avraamides, P.C. and Georgiou, G.M. (2012) Symptomatic Anomalous Right Coronary Artery Originating Superior to the Left Aortic Sinus with Interarterial Course in a Young Adult. Diagnosis with Multislice Computed Tomographic Coronary Angiography. Journal of Cardiovascular Medicine, 13, 148-151. http://dx.doi.org/10.2459/JCM.0b013e32833a05d3

[17] Sato, Y., Ichikawa, M., Komatsu, S., Matsuo, S., Kunimasa, T., Honye, J., Yoda, S., Matsumoto, N., Tani, S., Kasamaki, Y. and Saito, S. (2007) Multidetector Row Computed Tomographic Findings in a Patient with Anomalous Origin of the Right Coronary Artery from the Left Sinus of Valsalva. Cardiovascular Revascularization Medicine, 8, 60-62. http://dx.doi.org/10.1016/j.carrev.2006.03.105

[18] Ichikawa, M., Sato, Y., Komatsu, S., Hirayama, A., Kodama, K. and Saito, S. (2007) Multislice Computed Tomographic Findings of the Anomalous Origins of the Right Coronary Artery: Evaluation of Possible Causes of Myocardial Ischemia. The International Journal of Cardiovascular Imaging, 23, 353-360. http://dx.doi.org/10.1007/s10554-006-9165-9

[19] Turgut, O., Tandogan, I. and Dizman, R. (2009) Use of the RCB Guide in PCI of a Chronic Total Occlusion in an Anomalous Right Coronary Artery with High Anterior Takeoff. The Journal of Invasive Cardiology, 21, E70-E72.

[20] Yip, H., Chen, M.C., Wu, C.J., Yeh, K.H., Fu, M., Hang, C.L., Fang, C.Y. and Hsieh, K.Y. (2001) Primary Angioplasty in Acute Inferior Myocardial Infarction with Anomalous-Origin Right Coronary Arteries as Infarct-Related Arteries: Focus on Anatomic and Clinical Features, Outcomes, Selection of Guiding Catheters and Management. The Journal of Invasive Cardiology, 13, 290-297. 